\title{
Investigate the level of IL-8 in patients with diabetes mellitus and its relation with lipid profile and the incidence of atherosclerosis
}

\author{
Ammal Esmaeel Ibrahim \\ Department of Chemistry, College of Science, Al-Nahrain University, Baghdad, 10072, Iraq \\ *Corresponding author at: Department of Chemistry, College of Science, Al-Nahrain University, Baghdad, 10072, Iraq. \\ Tel.: +964.0790.1566784. Fax: +964.0790.1566784. E-mail address: dr.ammalalobaidi@yahoo.com (A.E. Ibrahim).
}

\section{ARTICLE INFORMATION}

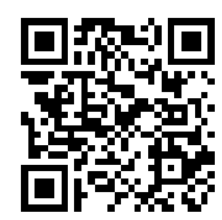

DOI: $10.5155 /$ eurjchem.5.3.529-531.1084

Received: 25 April 2014

Received in revised form: 23 May 2014

Accepted: 06 June 2014

Online: 30 September 2014

\section{KEYWORDS}

\section{Cholesterol}

Triglycerides

Interleukin-8

Atherosclerosis

Body mass index

Diabetes mellitus

\section{Introduction}

Interleukin-8 (IL-8) is a chemokine released from endothelial cells in response to inflammatory stimuli [1]. Interleukin-8 shows a high affinity for receptors on the plasma membranes of neutrophils. Cellular activation takes place after IL-8 binding in the presence of calcium and protein kinase, follow-on neutrophil activation and chemo taxis in infection and inflammation. Therefore IL-8 mediates neutrophil recruitment, accumulation, and activation [2]. Insulin is a peptide hormone, produced in pancreas by beta cells of Langerhans. The human insulin protein is composed of 51 amino acids; with a molecular weight of $5808 \mathrm{Da}$. Insulin consists from a dimer of an A-chain and a B-chain linked together by disulfide bonds. Insulin's structure varies slightly among species of animals. Insulin from animal sources differs somewhat in "strength" from that in humans because of those variations. Porcine insulin is especially close to the human version [3]. Hyperglycaemia accrue as results when insulin not work properly, this condition could be toxic to the body. When blood glucose levels drop below a physiological level, the body mobilizes stored sugar as an energy source through glycogenolysis, which hydrolyzes the glycogen stored in the liver and muscles into glucose, which can then be used as an energy source [3]. Diabetes mellitus is a systemic metabolic disease described by hyperglycemia, hyperlipidemia, hyperaminoacidemia, and hypoinsulinaemia that leads to reduction in both insulin secretion and insulin action. It is often linked with the development of micro and macro vascular diseases, which include neuropathy, nephropathy, cardiovascular and cerebrovascular diseases. Diabetes mellitus is associated with reduced quality of life and increased risk features for mortality and morbidity. The longstanding hyperglycemia is an important factor in the progression and development of micro- and macro-vascular problems [4].

This study was performed during the period from December 2012 to May 2013. This study includes fifty patients with diabetes mellitus. Patients, with range of 50-65 years old, were included in this study. Blood samples were taken from the patients after having thoroughly examined after exclusion of subjects with a history Acute Myocardial Infarction or any chronic diseases. Control groups contain forty healthy individuals who were matched for age, sex and Body Mass Index in this study as control group.

\section{Experimental}

\subsection{Blood collection and laboratory analysis}

Five milliliters of intravenous blood were taken from each control and patient. 
Table 1. Comparison between groups for Age, BMI, IL-8, lipid profile, glucose and insulin.

\begin{tabular}{|c|c|c|c|c|c|c|}
\hline Parameters & $\begin{array}{l}\text { Female patients } \\
(\text { no }=16)\end{array}$ & $\begin{array}{l}\text { Female control } \\
(\mathrm{no}=16)\end{array}$ & $p$-value & $\begin{array}{l}\text { Male patients } \\
(\text { no }=34)\end{array}$ & $\begin{array}{l}\text { Male control } \\
(\mathrm{no}=24)\end{array}$ & $p$-value \\
\hline Age years & $63.66 \pm 12.01$ & $62.45 \pm 6.09$ & 0.864 & $59.34 \pm 11.37$ & $58.76 \pm 7.09$ & 0.901 \\
\hline IL-8, g/mL & $50.15 \pm 16.37$ & $27.92 \pm 7.95$ & $<0.001$ & $54.11 \pm 22.33$ & $25.84 \pm 10.18$ & $<0.001$ \\
\hline Cholesterol, mg/dL & $191.70 \pm 5.03$ & $160.81 \pm 4.35$ & $<0.001$ & $179.52 \pm 23.28$ & $147.05 \pm 12.29$ & $<0.001$ \\
\hline Triglycerides, mg/dL & $155.86 \pm 25.09$ & $137.22 \pm 4.98$ & $<0.001$ & $169.03 \pm 4.87$ & $145.58 \pm 6.14$ & $<0.001$ \\
\hline VLDL-C, $\mathrm{mg} / \mathrm{dL}$ & $157.75 \pm 19.15$ & $139.29 \pm 5.09$ & $<0.001$ & $170.13 \pm 3.29$ & $144.82 \pm 7.19$ & $<0.001$ \\
\hline LDL-C, mg/dL & $155.87 \pm 5.78$ & 120.6210 .61 & $<0.001$ & $157.92 \pm 22.9$ & $148.73 \pm 16.71$ & $<0.001$ \\
\hline HDL, mg/dL & $35.09 \pm 5.83$ & $45.26 \pm 9.82$ & $<0.001$ & $29.88 \pm 5.99$ & $50.07 \pm 10.26$ & $<0.001$ \\
\hline BMI, $\mathrm{Kg} / \mathrm{m}^{2}$ & $30.90 \pm 3.84$ & $26.84 \pm 2.72$ & 0.713 & $29.71 \pm 4.79$ & $25.97 \pm 5.01$ & 0.811 \\
\hline Glucose, $\mathrm{mg} / \mathrm{dL}$ & $209.87 \pm 18.61$ & $90.34 \pm 16.42$ & $<0.001$ & $213.64 \pm 12.11$ & $95.83 \pm 9.27$ & $<0.001$ \\
\hline Insulin, IU/mL & $70.99 \pm 12.03$ & $29.89 \pm 7.47$ & $<0.001$ & $72.01 \pm 7.09$ & $30.29 \pm 8.12$ & $<0.001$ \\
\hline
\end{tabular}

Table 2. The correlation coefficient ( $r$ ) between IL-8 with Lipid profile, glucose and insulin between groups.

\begin{tabular}{lll}
\hline Parameters & Correlation coefficient, $\boldsymbol{r}($ Female patients no =16) & Correlation coefficient, $\boldsymbol{r}($ Male patients no $=\mathbf{3 4})$ \\
\hline Cholesterol & 0.522 & 0.512 \\
Triglycerides & 0.515 & 0.503 \\
VLDL-C & 0.514 & 0.505 \\
LDL-C & 0.416 & 0.426 \\
HDL & -0.302 & -0.263 \\
LDL/HDL & 0.317 & 0.324 \\
BMI & 0.498 & 0.501 \\
Glucose & 0.336 & 0.358 \\
Insulin & 0.403 & 0.417 \\
\hline
\end{tabular}

These samples were taken from fasting persons (at least 10 hours) between 8 a.m. and 9 a.m., the samples transported to plain tubes to determine lipid profile, insulin, glucose and IL-8. Leaving the blood non-heparinized in the tubes to be clotted. After that and in order to separate the serum, centrifugation of the sample was conducted for $5 \mathrm{~min}(4000 \mathrm{rpm}) .1 .0 \mathrm{~mL}$ serum was taken into strongly closed Eppendorf tubes and kept at -20 ${ }^{\circ} \mathrm{C}$ until examined. To omit kidney diseases, urea and Creatinine were analyzed in each serum sample (Table 1). IL-8 and insulin were determined by using ELISA kits (Table 1).

\subsection{Statistical analysis}

Statistical analysis was performed by statisticians using SPSS 15.01 Statistical Set for Social Sciences and also Excel 2003. Data for the experimental and test results were expressed as mean and stander error. The relationship constant used to find the connection among the calculated markers used a Pearson correlation. $p$-value of $\leq 0.05$ was taken as significant.

\section{Results and discussion}

During the last decade it has become more and more clear that the adipose tissue itself synthesizes and releases a group of cytokines and hormone-like proteins such as interleukin-6 (IL6) [5], tumor necrosis factor- $\alpha$ (TNF- $\alpha$ ) [6], leptin, plasminogen activator inhibitor-1 and adiponectin [7], all of which may be of importance for the association between obesity and health problems as shown in Table 2, the positive correlation between IL-8 and body mass index (BMI). It has lately been revealed by Bruun et al., [7] as well as by Gerhardt and coworkers [8] that IL-8 is produced and released from human mature isolated adipocytes as well as from cultured human adipose tissue fragments in a regulated manner. Interleukin-8 in addition to its association with a number of inflammatory processes, recently been implicated in the pathogenesis of atherosclerosis [9]. Study by Kopelman, P. G. reported that IL-8 was increased in obese subjects, and weight loss was not associated with a decrement in the circulating level of IL-8 [10]. Conversely, reports have previously demonstrated that changes in the circulating levels of IL-8 after weight loss were paralleled by changes in adipose tissue levels of IL-8 [11]. These new findings are of interest since chemokine such as IL-8 have been suggested to be involved in the pathogenesis of diseases associated with excess amounts of adipose tissue e.g. atherosclerosis and cardiovascular disease [9]. Gerszten et al., [12] reported that IL-8 stimulate the monocyte recruitment and fixed it's adhesion to endothelium and thus IL- 8 contributed in plaque formation. Ley and colleagues [13] have identified the chemokine KC (the mouse homolog of IL-8) as being the main chemokine that triggers monocyte capture in carotid arteries with early atherosclerotic lesions. Both mildly oxidized Low Density Lipoprotein (LDL), and TNF- $\alpha$ can induce IL-8 mRNA in endothelial cells [14]. An increase in circulating level of IL-8 can lead to increased insulin resistance, vascular inflammation, and the development of vascular disease [15]. In addition, it has been reported "that serum levels as well as urinary levels of IL8 were significantly increased in patients with type 2 diabetes with and without nephropathy" [16]. Atherosclerosis is a foremost risk factor of type 2 diabetes. Endothelial activation to bind monocytes is a key early event in these processes. The increase in IL-8 production seemed to be regulated at the transcriptional level, Suseela et al., [1] have found that glucose triggered IL-8 production through AP-1 and CHO-RE binding elements located within the human IL-8 promoter, which in turn, enhance monocyte: endothelial interactions. Stimulatingly, IL-8 may have multiple roles in mediating monocyte: endothelial interactions. First, as a secreted chemokine, it signals recruitment of monocytes [12]. The studies of Gerszten and colleagues [12] illustrated a new role for IL-8 in mediating monocyte rolling, and the recent elegant studies of Ley and colleagues [13] implicated $\mathrm{KC}$, the murine homolog of IL-8, as being the primary regulator of monocyte capture in atherosclerotic carotid arteries. Ley and colleagues found that KC was more important than monocyte chemotactic protein-1 (MCP-1) for mediating monocyte adhesion. Yeh and Berliner [14] have recently shown that IL-8 is a mediator of oxidized phospholipid activation of monocyte.

\section{Conclusions}

- Interleukin-8 positively correlated with BMI in patients and control groups and that lead us to consider IL-8 increases with obesity.

- Interleukin-8 positively correlated with LDL-cholesterol and negatively correlated with HDL-C thus makes us consider it as atherogenic factor.

- The increase in the level of IL-8 in patients who have diabetes mellitus may indicate increasing the incidence of atherosclerosis so this relation can indicate the tendency of patients toward atherosclerosis. 


\section{References}

[1]. Suseela, S.; Michael, Y.; Eric, C.; Melissa, E.; Hatley, A. E. Circ. Res. 2003, 92, 371-377.

[2]. Gross, M. D.; Shapiro, B.; Fig, L. M.; Steventon, R.; Skinner, R. W. S.; Hay, R. V. J. Nucl. Med. 2001, 42(11), 1656-1659.

[3]. American Society of Health-System Pharmacists (2009-02-01). Insulin Injection. PubMed Health. National Center for Biotechnology Information, U. S. National Library of Medicine. Retrieved 2012-10-12.

[4]. Rao, U. M.; Sreenivasulu, M.; Chengaiah, B.; Reddy, K. C.; Chetty, C. M. Int. J. PharmTech. Res. 2010, 2(3), 1883-1892.

[5]. Mohamed-Ali, V.; Goodrick, S.; Rawesh, A.; Katz, D. R.; Miles, J. M.; Yudkin, J. S. J. Clin. Endocr. Metab. 1997, 82, 4196-4200.

[6]. Hotamisligil, G. S.; Spiegelman, B. M. Diabetes 1994, 43, 1271-1278.

[7]. Bruun, J. M.; Pedersen, S. B.; Richelsen, B. J. Clin. Endocr. Metab. 2001, $86,1267-1273$

[8]. Gerhardt, C. C.; Romero, I. A.; Cancello, R.; Camoin, L.; Strosberg, A. D. Mol. Cell. Endocrinol. 2001, 175, 81-92.

[9]. Shin, W. S.; Szuba, A.; Rockson, S. G. Atherosclerosis 2002, 160, 91-102.

[10]. Kopelman, P. G. Nature 2000, 404, 635-643.

[11]. Bruun, J. M.; Pedersen, S. B.; Kristensen, K.; Richelsen, B. Obes. Res. 2002, 10, 499-506.

[12]. Gerszten, R. E.; Garcia-Zepeda, E. A.; Lim, Y. C.; Yoshida, M.; Ding, H. A.; Gimbrone, M. A. Jr.; Luster, A. D.; Luscinskas, F. W.; Rosenzweig, A. Nature 1999, 398, 718-723.

[13]. Huo, Y.; Weber, C.; Forlow, S. B.; Sperandio, M.; Thatte, J.; Mack, M. Jung, S.; Littman, D. R.; Ley, K. J. Clin. Invest. 2001, 108, 1307-1314.

[14]. Yeh, M.; Leitinger, N.; Martin, R.; Onai, N.; Matsushima, K.; Vora, D. K.; Berliner, J. A.; Reddy, S. T. Arterioscler. Thromb. Vasc. Biol. 2001, 21, 1585-1591.

[15]. Sushil, K.; Justin, L.; Jennifer, L. Antioxid. Redox Sign. 2007, 9(10), 1581-1590.

[16]. Richelse, J. M.; Bruun, C. V.; Soren, T.; Arne, A. Eur. J. Endocrinol. 2003, $148,535-542$ 